\title{
Ação multiprofissional contra as hepatites virais: um relato de experiência
}

\author{
Multiprofessional action against viral hepatitis: an experience report \\ Acción multiprofesional contra la hepatitis viral: un relato de experiencia
}

Recebido: 04/09/2021 | Revisado: 09/09/2021 | Aceito: 10/09/2021 | Publicado: 13/09/2021

\author{
Luana Lunardi Alban \\ ORCID: https://orcid.org/0000-0003-3842-9665 \\ Escola de Saúde Pública Municipal, Brasil \\ E-mail: luanalunardialban@hotmail.com \\ Gilson Fernandes da Silva \\ ORCID: https://orcid.org/0000-0001-9107-2656 \\ Escola de Saúde Pública Municipal, Brasil \\ E-mail: gilson_enfermeiro@hotmail.com \\ Bruna Emília Mareco de Almeida \\ ORCID: https://orcid.org/0000-0003-3333-7307 \\ Escola de Saúde Pública Municipal, Brasil \\ E-mail: brunaa.emilia@hotmail.com \\ Elias Córdova Schneider \\ ORCID: https://orcid.org/0000-0002-3631-551X \\ Escola de Saúde Pública Municipal, Brasil \\ E-mail: schneiderccordova@hotmail.com \\ Milena Sandri Sales \\ ORCID: https://orcid.org/0000-0001-9168-1531 \\ Escola de Saúde Pública Municipal, Brasil \\ E-mail: milena.sandri@gmail.com \\ Suely de Moura Santos de Sousa \\ ORCID: https://orcid.org/0000-0002-2947-9655 \\ Escola de Saúde Pública Municipal, Brasil \\ E-mail: suelyedusofia@hotmail.com
}

\begin{abstract}
Resumo
As hepatites virais constituem um problema de saúde pública, que gera elevadas taxas de morbidade e mortalidade. Em janeiro de 2019, a Lei $\mathrm{N}^{\mathrm{o}} 13.802$ instituiu o julho Amarelo, com o desenvolvimento de ações relacionadas à prevenção das hepatites virais. A oferta dos testes rápidos (TR) permite a deteç̧ão precoce dos vírus causadores das hepatites $\mathrm{B}$ e C, possibilitando a vinculação do paciente à assistência. Trata-se de um estudo descritivo, do tipo relato de experiência vivenciado pelos residentes em Saúde da Família, que ocorreu por meio da participação no evento intitulado "Ação multiprofissional contra as Hepatites Virais", realizado em um dos terminais transbordo da cidade de Cascavel, localizada no Oeste do Paraná. Percebem-se as elevadas taxas de HBV e HCV na região Sul, o que justifica as ações desenvolvidas pelos residentes, visto que foram realizados 211 testes para diagnóstico das hepatites B e C. O desenvolvimento das atividades mostrou-se como oportunidade de sensibilização da população, além de favorecer a capacitação dos residentes envolvidos como intermediadores da educação em saúde e proporcionaram maior aproximação com a comunidade. A atuação conjunta dos residentes, por meio das estratégias de rastreamento, fortalece os serviços de saúde e reflete na melhor qualidade de vida da comunidade.
\end{abstract}

Palavras-chaves: Hepatite viral; Prevenção; Educação em saúde; Programas de pós-graduação em saúde.

\begin{abstract}
Viral hepatitis is a public health problem responsible for high rates of morbidity and mortality. In January 2019, Law No. 13,802 instituted the Yellow July, with the development of actions related to the prevention of viral hepatitis. The offer of rapid tests allows early detection of the viruses that cause hepatitis B and C and assistance to the patient. This is a descriptive study of the experience report type experienced by residents in Family Health, which occurred in the event "Multidisciplinary action against Viral Hepatitis", held in one of the bus stations in Cascavel, a city located in western Paraná. The high rates of HBV and HCV in the South region are noticeable, which justifies the actions developed by the residents since 211 tests for diagnosis of hepatitis B and C were administered. The activities proved to be an opportunity to raise awareness among the population, besides favoring the training of the residents involved as intermediates of health education and to provide a closer approach to the community. The residents' action, through screening strategies, supports the health services and generates a better quality of life for the community.
\end{abstract}

Keywords: Viral Hepatitis; Prevention; Health education; Graduate health programs. 


\section{Resumen}

La hepatitis viral es un problema de salud pública que genera altas tasas de morbilidad y mortalidad. En enero de 2019, la Ley $\mathrm{N}^{\circ} 13.802$ instituyó el 'Julio amarillo', con el desarrollo de acciones relacionadas con la prevención de las hepatitis virales. La oferta de pruebas rápidas (RT) permite la detección precoz de los virus causantes de la hepatitis B y C, lo que permite vincular al paciente a la atención. Se trata de un estudio descriptivo, tipo relato de experiencia, a partir de lo vivido por los residentes en Medicina Familiar, que se produjo a través de la participación en el evento "Acción Multiprofesional contra la Hepatitis Viral", realizado en una de las terminales de transbordo de la ciudad de Cascavel, ubicada al oeste de Paraná. Se notan las altas tasas de VHB y VHC en la región Sur, lo que justifica las acciones realizadas por los residentes, ya que se realizaron 211 pruebas para diagnosticar hepatitis B y C. El desarrollo de actividades resultó ser una oportunidad para concientizar a la población, además de favorecer la formación de los residentes involucrados como intermediadores de la educación para la salud y brindar una mayor proximidad a la comunidad. La acción conjunta de los residentes, a través de estrategias de rastreo, fortalece los servicios de salud y refleja una mejor calidad de vida en la comunidad.

Palabras clave: Hepatitis viral; Prevención; Educación para la salud; Programas de posgrado en salud.

\section{Introdução}

As hepatites virais figuram-se como um problema de saúde pública, que gera altas taxas de morbimortalidade, ocasionadas por diferentes agentes etiológicos que apresentam características epidemiológicas e clínicas distintas, assim como às formas de transmissibilidade e consequências da infecção. Os tipos virais são classificados em hepatite A (HAV), hepatite B (HBV), hepatite C (HCV), hepatite D (HDV) e hepatite E (HEV) (Brasil, 2018).

A transmissão de forma fecal-oral ocorre nos vírus do tipo A e E, tendo interferência direta das condições de saneamento básico, higiene pessoal, qualidade da água e dos alimentos; já nos tipos B, C e D, são diversos os mecanismos de transmissão, como o parenteral, durante relações sexuais desprotegidas, compartilhamento de objetos contaminados, compartilhamento de seringas/materiais para uso de drogas injetáveis e inaláveis. Acidentes com materiais perfurocortantes também geram o risco de exposição, assim como procedimentos cirúrgicos, odontológicos e hemodiálises sem as adequadas normas de biossegurança (Brasil, 2015).

A transmissão vertical e no momento do parto, ocorre também nos casos dos vírus das hepatites B, C e D, sendo a via transplacentária incomum. Todas as gestantes devem fazer os testes rápidos para verificar uma possível infecção, além de atualização do calendário vacinal para o HEV, se necessário, após exames laboratoriais. Logo após o nascimento, o recémnascido deve receber a primeira dose da vacina contra HEV, preferencialmente nas primeiras 12 horas de vida. Se a gestante tiver $\mathrm{HBV}$, deve receber também a imunoglobulina contra a hepatite B, preferencialmente, ainda na sala de parto ou nas primeiras 12 horas de vida (Brasil, 2020).

Algumas populações são consideradas mais vulneráveis para a infecção pelas hepatites virais; destacam-se os usuários de drogas injetáveis e inaláveis, pessoas reclusas ou privadas de liberdade, instituições de menores, homossexuais, profissionais do sexo, portadores de Infecções Sexualmente Transmissíveis (ISTs), população de assentamentos e acampamentos, policiais, coletores de lixo e pessoas em situação de rua. Vale ressaltar que as ações de vigilância sanitária são recentes no Brasil; por essa razão, todas as pessoas com idade igual ou superior a 40 anos tornam-se grupos prioritários (Brasil, 2020).

Diante disso, em fevereiro de 2002, foi criado o Programa Nacional de Hepatites Virais, que tem como objetivo estabelecer diretrizes e estratégias junto aos diversos níveis do Sistema Único de Saúde (SUS), de maneira a sistematizar o cuidado, e ainda, possibilitando a identificação das hepatites e inserindo a abordagem dessa temática dentro das políticas de saúde, com vistas ao controle das infecções, e ampliação o acesso aos serviços de saúde (Brasil, 2002). Corroborando o referido programa, em janeiro de 2019, a Lei n 13.802 instituiu o Julho Amarelo, que deve ser realizado todos os anos, em todo o território nacional, com o desenvolvimento de ações relacionadas à prevenção das hepatites virais (Brasil, 2019). 
Podendo causar infecção crônica e, muitas vezes, assintomáticas, uma grande preocupação é o potencial de transmissão das Hepatites, assim, uma importante ação de prevenção são as ofertas dos testes rápidos (TR), os quais podem ser realizados em até 30 minutos não sendo necessário uma estrutura laboratorial, assim, esses testes são de extrema importância para a ampliação do acesso da população ao diagnóstico, pois permitem a detecção precoce dos vírus causadores das hepatites B e C, e dessa forma permite a vinculação do paciente à assistência (Brasil, 2018).

O Ministério da Saúde (MS) pela plataforma Telelab oferta capacitação na modalidade online para instrumentalizar os profissionais à realização dos TR. Após conclusão, o profissional estará apto para executá-los. Ao desenvolver ações de prevenção e promoção das Hepatites, por meio da educação em saúde, o profissional deve ter habilidade de comunicação, realizar uma escuta qualificada, ser sensível às demandas do indivíduo, ter conhecimento técnico e compromisso ético. O processo de aconselhamento extrapola o fato de apenas realizar o rastreamento dos indivíduos com o uso dos TR e pode se desenvolver em vários momentos, de forma coletiva ou individual (Brasil, 2005).

No município de Cascavel, a Atenção Primária à Saúde (APS) dispõe do Centro Especializado de Doenças Infectoparasitárias (CEDIP), bem como do Programa de Residência Multiprofissional em Saúde da Família, composto pelas áreas de Enfermagem, Odontologia e Serviço Social, gerenciado pela Escola de Saúde Pública Municipal, que tem por objetivo capacitar profissionais de saúde, por meio da formação em serviço, na modalidade de ensino em pós-graduação latosensu, para o desempenho de atividades no SUS (Secretaria Municipal de Saúde, 2018).

Assim, o Programa utiliza metodologias de aprendizagem visando qualificar os profissionais com competências para que possam atuar na Atenção Primária, de modo interdisciplinar e intersetorial. Dessa forma, deve-se adotar estratégias entre ensino, serviço e políticas públicas de saúde, a fim de construir novos conhecimentos que possam auxiliar a promoção da integralidade do cuidado, de maneira a gerar mudanças no modelo de atenção com a atuação dos profissionais residentes (Secretaria Municipal de Saúde, 2018).

Considerando que a atuação multiprofissional é fundamental para ações de prevenção e promoção da saúde, este relato tem por objetivo descrever a experiência dos residentes em Saúde da Família no evento "Ação multiprofissional contra as Hepatites Virais”, em consonância com a Campanha Julho Amarelo, no município de Cascavel, Paraná.

\section{Metodologia}

Trata-se de estudo com abordagem qualitativa, descritiva, do tipo relato de experiência, vivenciado pelos residentes, que ocorreu por meio da participação no evento intitulado “Ação multiprofissional contra as Hepatites Virais", realizado em um dos terminais rodoviários de transbordo na cidade de Cascavel, localizada no Oeste do Paraná. Nesse sentido, a pesquisa qualitativa busca compreender o comportamento das pessoas, conhecimentos, opiniões, atitudes e crenças (Vieira \& Hossne, 2015). Desse modo, a pesquisa qualitativa não busca quantificar, mas por meio dela o pesquisador mantém contato direto e interativo com o objeto de estudo, direcionando o desenvolvimento de pesquisas que permitam respostas para as situações identificadas, de forma a entender, descrever e interpretar fatos encontrados (Proetti, 2017).

As atividades foram desenvolvidas no dia 14 de julho, das 8:00 às 17:00 horas por cinco residentes de Enfermagem, quatro residentes da Odontologia e quatro do Serviço Social do Programa de Residência Multiprofissional em Saúde da Família (PRMSF), supervisionados pela Enfermeira coordenadora do CEDIP, parceiro do evento e pelo Coordenador e Tutor do PRMSF. O trabalho da equipe multiprofissional na APS é realizado por diferentes profissionais, sendo de extrema importância para a garantia de um atendimento integral, o que corrobora com os princípios do Sistema Único de Saúde (SUS), prestando uma assistência que perpassa todas as necessidades do indivíduo assistido (Evangelista et. al., 2016). 
Anteriormente ao evento, foram realizadas discussões sobre as Hepatites Virais, com pesquisa documental e bibliográfica, além do planejamento das ações durante encontros do grupo de estudos intitulado "Compartilhando Saberes", composto pelos residentes do primeiro ano da residência.

Para a realização da ação, foi montada toda uma estrutura a fim de atrair a atenção daqueles que por ali transitavam. Assim, o local foi decorado e utilizou-se de um stand, composto por: uma faixa confeccionada pelos organizadores descrevendo os tipos de Hepatites Virais, material impresso (flyers informativos, cartazes, folhas com questionários) sobre as formas de prevenção e evidenciando a Campanha Julho Amarelo, bem como preservativos masculinos e femininos, com o intuito de sensibilizar a população da importância do diagnóstico precoce e prevenção das Hepatites.

Cabe ressaltar que foram atendidas as normas dispostas nas Resoluções 466/12 e 510/2016, do Conselho Nacional de Saúde (CNS), não sendo submetido ao Comitê de Ética em Pesquisa (CEP), visto que se trata de um relato de experiência.

\section{Resultados e Discussão}

Durante a ação os usuários eram abordados enquanto esperavam pelo transporte público e, nesse momento, os residentes da Odontologia e Serviço Social realizavam orientações sobre formas de prevenção das Hepatites, enfatizavam a importância da detecção precoce da doença por meio dos Testes Rápidos disponíveis no local; em seguida, os usuários que demonstraram interesse em realizar os testes eram encaminhados a outro stand em local mais reservado. Foram abordadas para orientações em torno de 500 pessoas, de acordo com o fluxo do terminal rodoviário de transbordo na cidade de Cascavel.

Foram realizados 211 testes para diagnósticos das hepatites B e C pelos profissionais residentes de Enfermagem, previamente capacitados. Do total de testes três foram reagentes, sendo dois deles para Hepatite B e um para Hepatite C, apenas um dos usuários conhecia seu diagnóstico, assim, após a leitura dos testes, os laudos com os resultados eram preenchidos pelos cinco profissionais enfermeiros, os quais foram carimbados, assinados e, posteriormente entregues ao paciente de maneira sigilosa. Se o resultado fosse reagente, os usuários eram orientados e encaminhados ao CEDIP para acompanhamento; se o resultado fosse não reagente, eram reforçadas as formas de prevenção e novo TR, respeitando a janela imunológica.

A ação contra as Hepatites Virais possibilitou o desenvolvimento do trabalho multiprofissional e uma reflexão sobre o tema em questão. Houve mobilização no sentido de direcionar a população para a realização dos testes rápidos, orientações sobre prevenção, enfatizando a imunização da Hepatite B e, também, a distribuição de preservativos e folders com linguagem clara e objetiva para toda a população, abordando as formas de contágio e meios de prevenção das Hepatites.

No decorrer da ação, notou-se uma certa apreensão da população em adquirir preservativos no local onde foram expostos. Com base nisso, os preservativos foram levados para os banheiros por serem locais mais discretos, proporcionando acesso sem "constrangimento" e garantindo a privacidade. Esse receio pode acontecer por questões morais, culturais e religiosas que, ao longo do tempo, influenciam a construção da sexualidade (Brasil, 2010).

Destaca-se que o público com maior aceitação da abordagem, para as orientações e realização dos TR, foram os idosos, enquanto os mais jovens apresentaram resistência. Segundo Fontes, Crivelaro, Scartezini, Lima, Garcia e Fujioka (2017): “A vulnerabilidade do jovem brasileiro é alta, juntando esse fator a percepção de riscos de IST,s é muito baixa, o entendimento dessa vulnerabilidade junto a percepção de seus determinantes sociais é de suma importância para o desenvolvimento de programas e políticas públicas."

A realização da ação no Terminal Urbano Oeste, escolhida pelo fato de comtemplar maior público, facilitou o acesso aos serviços ofertados pelo SUS, pois, muitas vezes, os usuários não conseguem ir até os serviços de saúde por conta do horário da jornada de trabalho. Nessa perspectiva, a realização dessa ação atende aos princípios da universalidade e 
integralidade, enfatizando que é possível promover saúde em qualquer ambiente.

Houveram de 1999 a 2020, no Brasil, 254.389 pessoas foram diagnosticadas com o vírus da hepatite B e 262.815 com o vírus da hepatite C. A região Sul foi a $2^{\mathrm{a}}$ maior em notificações por Hepatite B e teve $27,5 \%$ dos casos de Hepatite C. Nesse mesmo período e no estado do Paraná, foram confirmados 30.791 casos de Hepatite B e 13.552 casos para Hepatite C (Brasil, 2021).

Percebem-se as elevadas taxas de HBV e HCV, na região Sul, o que justifica as ações desenvolvidas pelos residentes em saúde da família, pois a oferta dos testes rápidos e a Educação em Saúde são estratégias para a ampliação do diagnóstico precoce, o que também possibilita o encaminhamento oportuno das pessoas infectadas para o tratamento adequado. Isso impacta diretamente a qualidade de vida e previne complicações mais frequentes, como cirrose avançada e câncer hepático (Brasil, 2018).

Nessa perspectiva, as práticas educativas em saúde exigem a implementação de um processo teórico e prático, que visa às exigências das políticas de educação e de saúde. Portanto, a inserção de atividades de Educação em Saúde na formação de residentes da área da saúde contribui para uma prática social de promoção de saúde e sensibiliza para o desenvolvimento de uma consciência crítica-reflexiva (Moreira et al., 2019).

Assim, essa integração com a população representa uma experiência significativa na construção de conhecimento adequado às suas necessidades de saúde. Dessa maneira, inserir na formação acadêmica as práticas de educação em saúde contribui para uma formação de qualidade a partir das demandas do território (Viana et al., 2015).

\section{Considerações Finais}

O desenvolvimento das atividades preventivas contra as hepatites virais mostrou-se como oportunidade de sensibilização da população, além de favorecer a capacitação dos residentes envolvidos, como principais intermediadores da educação em saúde, e possibilitando maior aproximação com a comunidade.

Portanto, a abordagem contribuiu de maneira positiva para os usuários, que passaram a ter uma melhor compreensão sobre as hepatites virais e que poderão servir como disseminadores desse conhecimento no meio familiar e na comunidade em que vivem.

Diante desse cenário, a Residência Multiprofissional em Saúde da Família possibilita aos residentes a atuação sobre a realidade encontrada com uma visão crítica e reflexiva, realizando busca ativa da população, além de desenvolver educação em saúde, o que resulta na prevenção e promoção da saúde; também, oferece suporte ao diagnóstico precoce de doenças infectocontagiosas. A atuação conjunta dos residentes, por meio das estratégias de rastreamento, fortalece os serviços de saúde e reflete na melhor qualidade de vida da comunidade.

\section{Referências}

Brasil. Ministério da Saúde. (2019). Lei $N^{o}$ 13.802, de 10 de janeiro de 2019. Institui o julho Amarelo, a ser realizado a cada ano, em todo o território nacional, no mês de julho, quando serão efetivadas ações relacionadas à luta contra as hepatites virais.

Brasil. Ministério da Saúde. (2002). Secretaria de Políticas de Saúde. Programa Nacional de Hepatites Virais. Programa Nacional de Hepatites Virais: avaliação da assistência as hepatites virais no Brasil.

Brasil. Ministério da Saúde. (2005). Secretaria de Vigilância em Saúde. Departamento de Vigilância Epidemiológica. Manual de aconselhamento em hepatites virais.

Brasil. Ministério da Saúde. (2010). Secretaria de vigilância em saúde. Programa Nacional de DST e AIDS. Diretrizes para implantação do projeto Saúde e Prevenção nas Escolas.

Brasil. Ministério da Saúde. (2012). Conselho Nacional de Saúde, Comissão Nacional de Ética em pesquisa. Resolução no 466, de 12 de dezembro de 2012. Dispõe sobre as diretrizes e normas regulamentadoras de pesquisas envolvendo seres humanos. 
Research, Society and Development, v. 10, n. 12, e55101220235, 2021

(CC BY 4.0) | ISSN 2525-3409 | DOI: http://dx.doi.org/10.33448/rsd-v10i12.20235

Brasil. Ministério da Saúde. (2015). Secretaria de Vigilância em Saúde. Departamento de DST, Aids e Hepatites Virais. O Manual Técnico para o Diagnóstico das Hepatites Virais.

Brasil. Ministério da Saúde. (2016). Conselho Nacional de Saúde, Comissão Nacional de Ética em pesquisa. Resolução no 510 , de 07 de abril de 2016. Dispõe sobre as normas aplicáveis a pesquisas em Ciências Humanas e Sociais cujos procedimentos metodológicos envolvam a utilização de dados diretamente obtidos com os participantes ou de informações identificáveis ou que possam acarretar riscos maiores do que os existentes na vida cotidiana, na forma definida nesta Resolução.

Brasil. Ministério da Saúde. (2017). Portaria no 2.436, de 21 de setembro de 2017. Aprova a Política Nacional de Atenção Básica, estabelecendo a revisão de diretrizes para a organização da Atenção Básica, no âmbito do Sistema Único de Saúde (SUS).

Brasil. Ministério da Saúde. (2018). Secretaria de Vigilância em Saúde. Departamento de Vigilância, Prevenção e Controle das Infecções Sexualmente Transmissíveis, do HIV/Aids e das Hepatites Virais. Manual Técnico para o Diagnóstico das Hepatites Virais.

Brasil. Ministério da Saúde. (2020). Secretaria de Vigilância em Saúde. Departamento de Doenças de Condições Crônicas e Infecções Sexualmente Transmissíveis. A B C D E das hepatites virais para agentes comunitários de saúde.

Brasil. Ministério da Saúde. Secretaria de vigilância em saúde. (2021). Boletim Epidemiológico das Hepatites Virais.

Evangelista, V. C., Domingos, T. S., Siqueira, F. P. C., \& Braga, E. M. (2016). Equipe multiprofissional de terapia intensiva: humanização e fragmentação do processo de trabalho. Revista Brasileira de Enfermagem, 69(6), 1099-1107.

Fontes, M. B., Crivelaro, R. C., Scartezini, A. M., Lima, D. D., Garcia, A. A., \& Fujioka, R. T. (2017). Fatores determinantes de conhecimentos, atitudes e práticas em DST/Aids e hepatites virais, entre jovens de 18 a 29 anos, no Brasil. Ciência \& Saúde Coletiva, 22(4), 1343-1352.

Moreira, M. N., Silva, M. P. C., Duarte, A. P. G. M., Resende, M. P., Amaral, J. B. D., \& Contim, D. (2019). Educação em saúde no ensino de graduação em Enfermagem. Revista de Enfermagem e Atenção à Saúde, 8(1), 61-70.

Proetti, S. (2018). As pesquisas qualitativa e quantitativa como métodos de investigação científica: Um estudo comparativo e objetivo. Revista Lumen, 2(4).

Secretaria Municipal de Saúde (SMS). (2018). Escola de Saúde Pública Municipal. Projeto Político Pedagógico do Programa de Residência Multiprofissional em Saúde da Família. Cascavel-Paraná.

Vieira, F. S., Portela, N. L. C., Sousa, G. C., Costa, E. S., Oliveira, D. E. P., \& Neiva, M. J. L. M. (2017). Inter-relação das ações de educação em saúde no contexto da estratégia saúde da família: percepções dos enfermeiros. Revista de Pesquisa Cuidado é Fundamental Online, 9(4), 1139-1144.

Vieira, S., \& Hossne, W. S. (2015). Metodologia Científica para a área da saúde. (2 ${ }^{\mathrm{a}}$ ed.), Elsevier. 